\title{
Kontrol Gerak Robot Lengan Menggunakan Handphone
}

\author{
Ariyono Setiawan \\ Program Studi D3 Teknik Telekomunikasi dan Navigasi Udara \\ Akademi Teknik dan Keselamatan Penerbangan Surabaya \\ Jemur Andayani I/73 Wonocolo Surabaya 60236 \\ Telp. (031)8410871, Fax. (031) 8490005 \\ Email : rmaryo4u@gmail.com
}

\begin{abstract}
At this time the development and technological advances encourage the people to change the ordinary life style extra ordinary life style, sophisticated, modern, and still give priority to security that become relatively high. Therefore human is required in order to adapt twith the condition that exist at this time. One of them is the development in the robotics world. Because the benefits of robot is very important in helping the human job or replace the role of humans life, either in industry or in other sector that have a control system respectively. Therefore designed a robot arm control system using a communication device that is familiar and almost every people use it. That is a handphone. The working principle of that device a command or input from handphone then transmitted to electronic circuit that used bluetooth media. There is also bluetooth at the circuit that work to continue use data or command from handphone. On microcontroller using IC ATMEGA 16 and the programing language C. From the microcontroller has set the motor DC on robot arm. Which will be driver according with instruction that given by that handphone
\end{abstract}

Keyword : Arm Robot, Bluetooth, Handphone

\section{PENDAHULUAN}

Teknologi memegang peran penting di era modernisasi seperti pada saat ini, dimana teknologi telah menjadi bagian yang tidak dapat dipisahkan dalam kehidupan sehari-hari. Perkembangan teknologi saat ini telah merambah ke segala aspek kehidupan sehingga saat ini seolah kita dimanjakan oleh adanya alat-alat yang dapat memberikan banyak kemudahan. Dengan berkembangnya ilmu pengetahuan dan teknologi, Mobile phone/ hand phone yang dahulu hanya digunakan sebagai alat komunikasi saja, kini sudah berkembang dan mempunyai banyak fungsi. Mobile phone merupakan salah satu peralatan elektronik yang pada saat ini menjadi salah satu multimedia yang banyak digunakan oleh masyarakat. Fungsi mobile phone antara lain adalah alat komunikasi, media informasi, browser, sarana hiburan dan lain-lain. Desain dan fiturnya pun juga ikut berkembang. Perkembangan teknologi di bidang robotika dan penerapannya di beberapa sektor industri sangat pesat, oleh karena itu menarik untuk ditelusuri. Salah satu hal penting yang menjadi perhatian adalah bagaimana membuat robot dapat berfungsi dengan benar dan mampu melakukan perintah yang diberikan melalui sebuah kontroler untuk mengendalikan robot secara langsung atau melalui komputer. Robot lengan merupakan bentuk robot yang banyak digunakan pada industri- industri maju. Karenanya, pembahasan mengenai bagaimana sebuah robot lengan dapat dikendalikan merupakan hal yang menarik untuk disampaikan

\section{Fitur-fitur arm robot}

1. Lima Axis gerak:

2. Basis dapat memutar kiri dan kanan $-350^{\circ}$.

3. Bahu bergerak kisaran $-120^{\circ}$.

4. Siku bergerak kisaran $-135^{\circ}$. 
5. Pergelangan tangan memutar $\mathrm{CW}$ dan $\mathrm{CCW}-340^{\circ}$.

6. Gripper membuka dan menutup-55 mm (2,2 inci) - 0 .

7. Dimensi Produk-Maksimum panjang keluar - $360 \mathrm{~mm}$ (14,2 inci).

8. Ketinggian maksimum atas-510 $\mathrm{mm}(20,1$ inci).

9. Mengangkat Kapasitas Maksimum-130g (4,6 oz.) Daya.

10. Sumber Listrik: 4 "D" baterai (tidak termasuk)

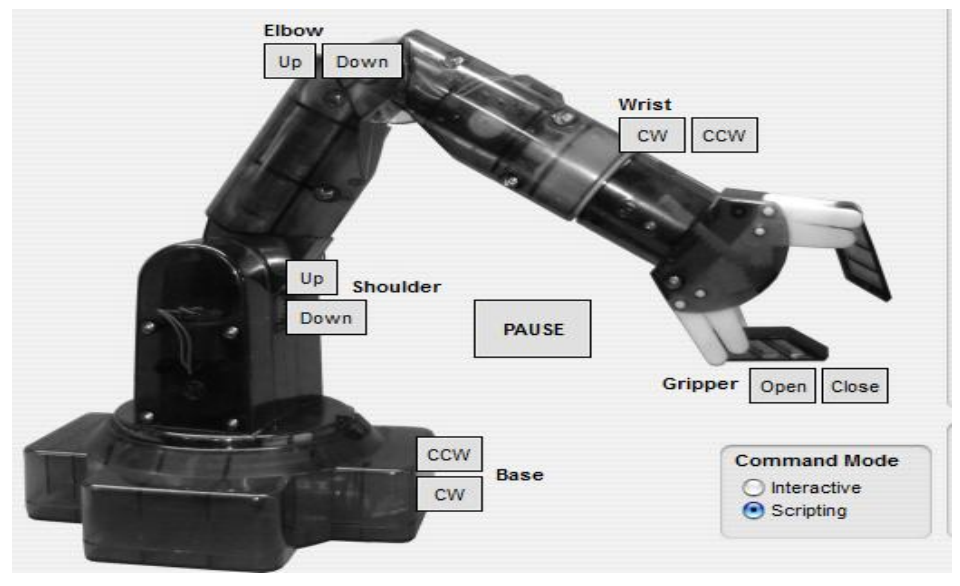

Gambar Arm Robot

Tabel Akses gerak Arm Robot

\begin{tabular}{|c|c|c|c|}
\hline No & Nama Sendi & Jenis & Gerakan \\
\hline 1. & Base & CW & CCW \\
\hline 2. & Shoulder & UP & DOWN \\
\hline 3. & Elbow & UP & CCW \\
\hline 4. & Wrist & CW & CLOSE \\
\hline 5. & Gripper & OPEN & \\
\hline
\end{tabular}

\section{PERANCANGAN SISTEM}

\section{Blok Diagram Rancangan}

Konsep dasar dari rancangan yaitu menggerakkan lengan robotic sesuai dengan perintah maka penulis merancang alat tersebut dimana input berupa gerak dari android mobile tersebut kemudian ditransmisikan melalui bluetooth. Kemudian perintah tersebut diterima oleh bluetooth module, selanjutnya perintah tersebut dikirimkan lagi pada rangkaian mikrokontroller dengan melalui port serial. Sehingga output dari mikrokontroller dapat menggerakkan motor dc yang ada didalam lengan robotic sesuai dengan android yang kita gerakkan 


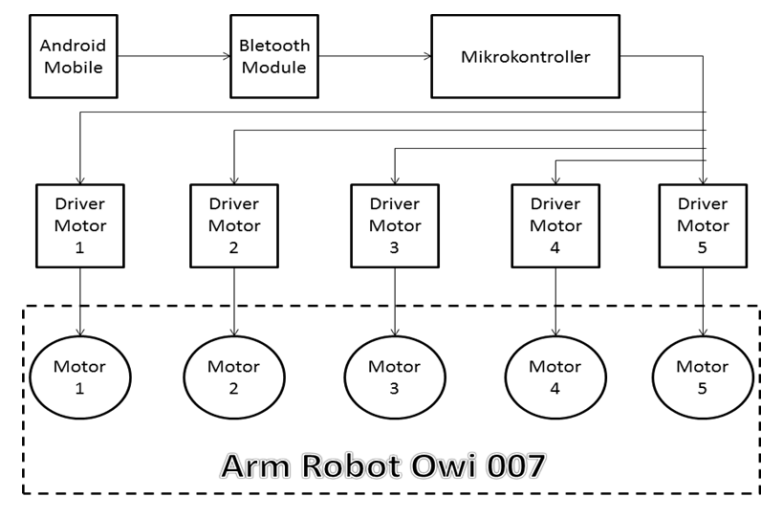

Gambar Blok Diagram

Dari blok diagram diatas dapat dijelaskan bahwa input dari android yang berupa gerakan di transmisikan melalui bluetooth pada handphone. Kemudian perintah tersebut diterima oleh modul bluetooth. Jarak sistem menggunakan bluetooth tersebut sekitar 10 - 30 meter. Dan menggunakan bluetooth tersebut hanya dapat dilakukan di area terbuka tanpa ada halangan. Modul Bluetooth tersebut sebagai perantara atau penyalur perintah gerak dari android tersebut ke mikrokontroler ATMEGA 16. Dari bluetooth ke mikrontroller tersebut dihubungkan menggunakan serial port. Kemudian mikrontroller tersebut akan memberikan perintah pada driver masing-masing motor. Kemudian dari driver tersebut dapat menggerakan semua motor/sendi-sendi dari lengan robotic tersebut sesuai dengan perintah gerak dari android mobile tersebut.

\section{LISTING PROGRAM ANDROID}

/* Program untuk mengontrol robot lengan*/ package com.example.android.BluetoothChat; import android.widget.RadioButton; @SuppressLint(\{ "NewApi", "NewApi", "NewApi", "NewApi", "NewApi", "NewApi", "NewApi", "NewApi", "NewApi" \}) public class BluetoothChat extends Activity \{ // Debugging private static final String TAG = "BluetoothChat"; private static final boolean $\mathrm{D}=$ true; private static boolean gyrox = false,send_sensor=false; private static boolean flagStop = true; // Message types sent from the BluetoothChatService Handler public static final int MESSAGE_STATE_CHANGE = 1; public static final int MESSAGE_READ = 2; public static final int MESSAGE_WRITE $=3$; public static final int MESSAGE_DEVICE_NAME $=4$; public static final int MESSAGE_TOAST $=5$ 


\section{Flowchart}

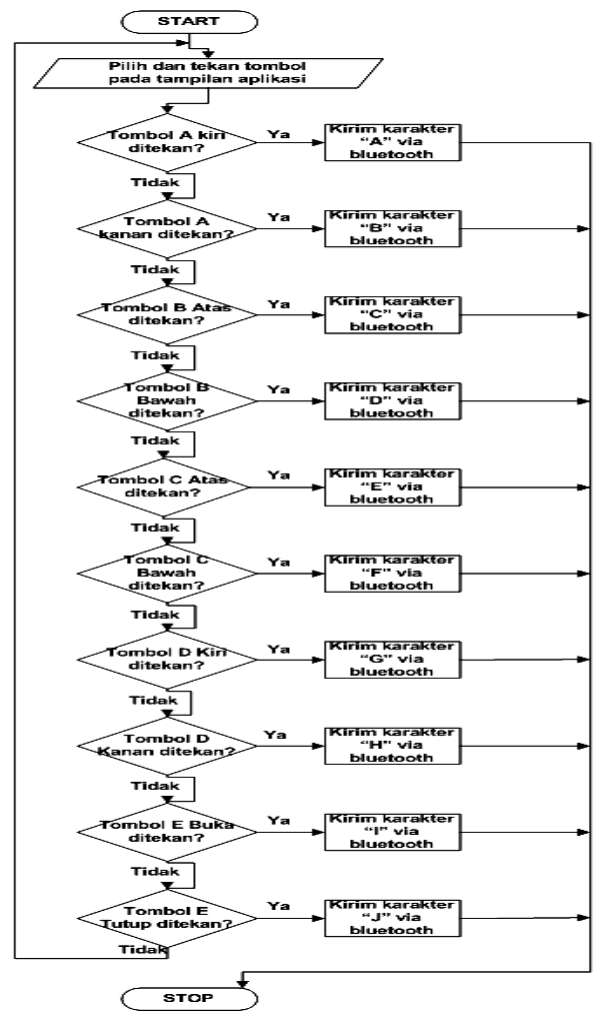

Gambar 3.2 : Flowchart Pengirim

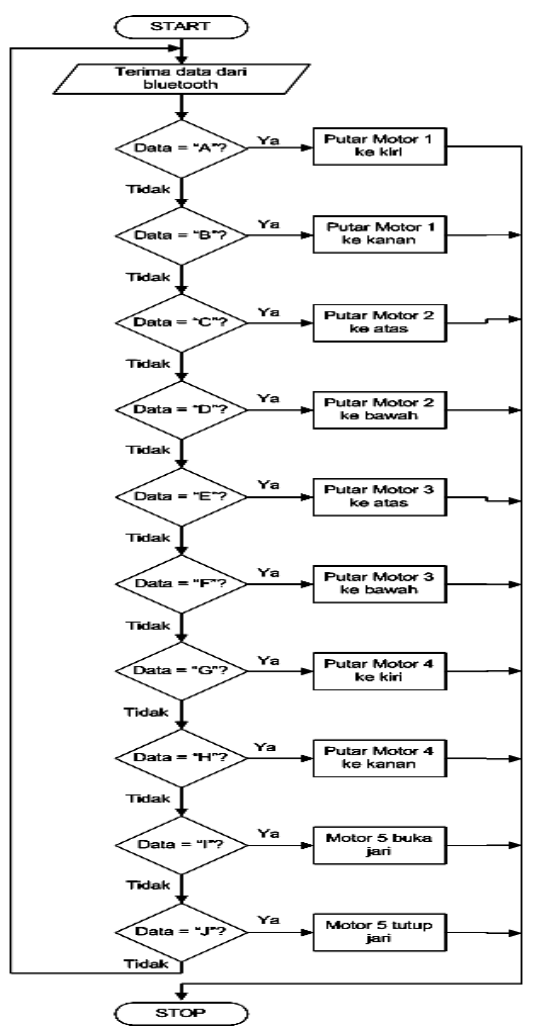

Gambar 3.3 : Flowchart Penerima 


\section{CARA KERJA RANGKAIAN/SISTEM}

Sistem robot menggunakan mikrokontroler ATMEGA 16 untuk mengolah semua data. Komunikasi data yang dilakukan HP Android dengan mikrokontroler berbasis komunikasi serial nirkabel dengan menggunakan bluetooth sebagai media pengiriman data. Data yang dikirim dari HP Android adalah data dengan lebar 8 bit berbentuk karakter- karakter tertentu dengan kecepatan pengiriman sebesar 9600bps. Sehingga ketika mikrokontroler menerima data melalui serial bluetooth module (DF Bluetooth V3), akan mengartikan data tersebut sebagai perintah untuk menggerakkan motor-motor pada lengan robot. Tentu saja sebelumnya perintah-perintah itu sengaja disinkronkan antara HP Android dengan mikrokontroler, sehingga tidak sampai salah arti. HP android ditanamkan sebuah aplikasi berupa button-button seperti halnya di Visual basic, tetapi untuk aplikasi ini dibuat dengan menggunakan Eclipse Juno. Ketika salah satu button tersebut ditekan, misalnya button LEFT pada motor A, maka akan mengirimkan data karakter 'a' ke miikrokontroler. Setelah data itu diterima mikrokontroler, data ' $\mathrm{a}$ ' tadi diartikan mikrokontroler sebagai perintah untuk menggerakan motor lengan A ke kiri. Dilengkapi pula penggunaan sensor accelerometer(G-Sensor) pada HP Android untuk diambil data Y-axisnya yang nantinya data itu dikirimkan ke mikrokontroler untuk mengontrol salah satu motor pada lengan robot. Sebagai ilustrasi penggunaan sensor ini, ketika HP Android dimiringkan ke kiri makan lengan robot berputar ke kiri, ketika HP android dimiringkan ke kanan maka lengan robot juga ikut berputar ke kanan, dan ketika HP Android sejajar secara horisontal makan lengan robot diam.

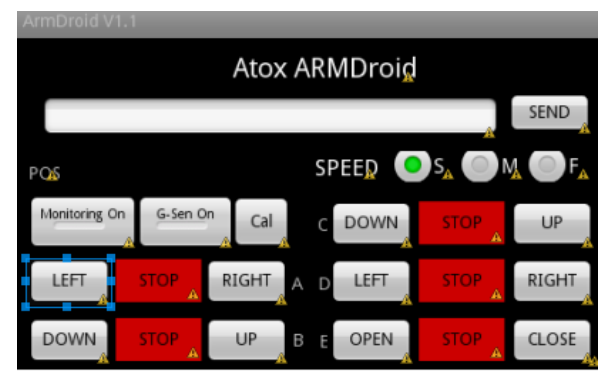

Gambar Tampilan Aplikasi Pada Android Mobile

Sistem hardware pada robot terdiri dari beberapa bagian penting, yaitu :

\section{ATMEGA 16}

Mikrokontroler yang digunakan adalah ATMEL ATMEGA16. Alasan menggunakan jenis chip ini adalah

1. Kebutuhan jumlah PORT yang cukup banyak yaitu 23 buah.

2. Kebutuhan akan komunikasi serial.

3. Kebutuhan akan ruang memori yang relatif besar apabila nantinya dikembangkan lebih lanjut.

4. Kemudahan mencari chip ini di pasaran.

5. Terjangkaunya harga di pasaran.

Dengan kelima alasan di atas, sehingga pilihan mengerucut pada ATMEGA16. Minimum system ini menggunakan external clock dari kristal dengan frekuensi 11,059200 MHz. Clock dengan nilai seperti ini mampu mereduksi error komunikasi serial hingga $0 \%$. Tugas utama dari minimum system ini adalah mengolah semua data yang masuk menjadi sebuah perintah gerakan ke robot lengan.

\section{LCD}


LCD difungsikan untuk menampilkan data yang masuk beserta perintah yang dikerjakan mikrokontroler.

\section{PUSH BUTTON}

Push button difungsikan untuk start sistem. Setelah push button OK ditekan, maka sistem mulai aktif. Ketika push button ditekan, logika yang dikeluarkan adalah 'low'

\section{SERIAL BLUETOOTH MODULE}

Serial bluetooth module ini menerima data dari bluetooth pada HP Android. Komunikasi diantara keduanya adalah komunikasi serial dengan kecepatan 9600bps.

\section{MOTOR DRIVER}

Motor driver berfungsi untuk menjalankan motor-motor pada lengan robot dengan daya yang cukup. Motor driver ini menggunakan relay untuk mengatur arah putaran motor dan transistor power TIP32 untuk menguatkan sinyal PWM. PWM disini difungsikan sebagai pengaturan kecepatan motor. Sistem didesain dengan 3 kecepatan, yaitu Slow, Mediam, dan Fast

\section{PENGUJIAN DAN ANALISA}

\section{Parameter Ukur}

1. Handphone Smartfren Hisence E860 android.

2. Ketinggian \pm 3 meter dari tanah.

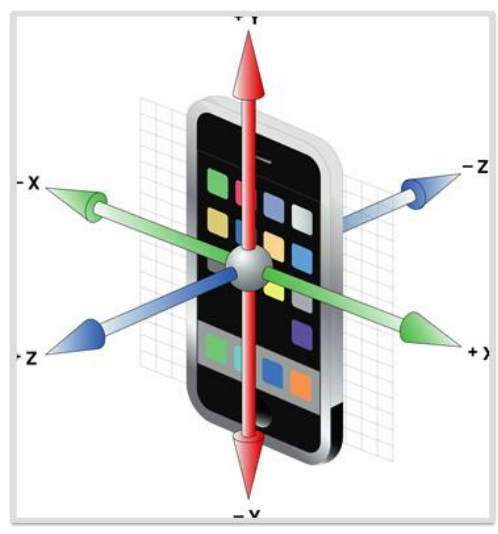

Gambar Posisi Accelerometer ( x, y, z )

\section{Pengukuran dan Analisa}

Berdasarkan Gravitasi terukur $\mathrm{Z}=10.15 \mathrm{~m} / \mathrm{s}^{2}$ pada saat handphone dalam posisi terlentang

Tabel Data X-Axis

\begin{tabular}{|c|c|}
\hline $\begin{array}{c}\text { SUDUT } \\
\text { KEMIRINGAN }\end{array}$ & DATA X AXIS \\
\hline $\mathbf{9 0}^{\mathbf{0}}$ & $9,04 \mathrm{~m} / \mathrm{s}^{2}$ \\
\hline $\mathbf{8 0}^{\mathbf{0}}$ & $8.12 \mathrm{~m} / \mathrm{s}^{2}$ \\
\hline $\mathbf{7 0}^{\mathbf{0}}$ & $7.13 \mathrm{~m} / \mathrm{s}^{2}$ \\
\hline $\mathbf{6 0}^{\mathbf{0}}$ & $6.09 \mathrm{~m} / \mathrm{s}^{2}$ \\
\hline $\mathbf{5 0}^{\mathbf{0}}$ & $5.08 \mathrm{~m} / \mathrm{s}^{2}$ \\
\hline $\mathbf{4 0}^{\mathbf{0}}$ & $4.06 \mathrm{~m} / \mathrm{s}^{2}$ \\
\hline $\mathbf{3 0}^{\mathbf{0}}$ & $3.03 \mathrm{~m} / \mathrm{s}^{2}$ \\
\hline $\mathbf{2 0}^{\mathbf{0}}$ & $2.03 \mathrm{~m} / \mathrm{s}^{2}$ \\
\hline $\mathbf{1 0}^{\mathbf{0}}$ & $1.07 \mathrm{~m} / \mathrm{s}^{2}$ \\
\hline
\end{tabular}




\begin{tabular}{|c|c|}
\hline $\mathbf{0}^{\mathbf{0}}$ & 0 \\
\hline $\mathbf{- 1 0}^{\mathbf{0}}$ & $1.05 \mathrm{~m} / \mathrm{s}^{2}$ \\
\hline $\mathbf{- 2 0}^{\mathbf{0}}$ & $2.07 \mathrm{~m} / \mathrm{s}^{2}$ \\
\hline $\mathbf{- 3 0}^{\mathbf{0}}$ & $3.10 \mathrm{~m} / \mathrm{s}^{2}$ \\
\hline $\mathbf{- 4 0}^{\mathbf{0}}$ & $4.06 \mathrm{~m} / \mathrm{s}^{2}$ \\
\hline $\mathbf{- 5 0}^{\mathbf{0}}$ & $5.03 \mathrm{~m} / \mathrm{s}^{2}$ \\
\hline $\mathbf{- 6 0}^{\mathbf{0}}$ & $6.09 \mathrm{~m} / \mathrm{s}^{2}$ \\
\hline $\mathbf{- 7 0}^{\mathbf{0}}$ & $7.07 \mathrm{~m} / \mathrm{s}^{2}$ \\
\hline $\mathbf{- 8 0}^{\mathbf{0}}$ & $8.01 \mathrm{~m} / \mathrm{s}^{2}$ \\
\hline $\mathbf{- 9 0}^{\mathbf{9}}$ & $9.08 \mathrm{~m} / \mathrm{s}^{2}$ \\
\hline
\end{tabular}

Tabel Data Y-Axis

\begin{tabular}{|c|c|}
\hline $\begin{array}{c}\text { SUDUT } \\
\text { KEMIRINGAN }\end{array}$ & DATA Y AXIS \\
\hline $\mathbf{9 0}^{\mathbf{0}}$ & $9.03 \mathrm{~m} / \mathrm{s}^{2}$ \\
\hline $\mathbf{8 0}^{\mathbf{0}}$ & $8.04 \mathrm{~m} / \mathrm{s}^{2}$ \\
\hline $\mathbf{7 0}^{\mathbf{0}}$ & $7.06 \mathrm{~m} / \mathrm{s}^{2}$ \\
\hline $\mathbf{6 0}^{\mathbf{0}}$ & $6.07 \mathrm{~m} / \mathrm{s}^{2}$ \\
\hline $\mathbf{5 0}^{\mathbf{0}}$ & $5.02 \mathrm{~m} / \mathrm{s}^{2}$ \\
\hline $\mathbf{4 0}^{\mathbf{0}}$ & $4.05 \mathrm{~m} / \mathrm{s}^{2}$ \\
\hline $\mathbf{3 0}^{\mathbf{0}}$ & $3.06 \mathrm{~m} / \mathrm{s}^{2}$ \\
\hline $\mathbf{2 0}^{\mathbf{0}}$ & $2.07 \mathrm{~m} / \mathrm{s}^{2}$ \\
\hline $\mathbf{1 0}^{\mathbf{0}}$ & $1.03 \mathrm{~m} / \mathrm{s}^{2}$ \\
\hline $\mathbf{0}^{\mathbf{0}}$ & 0 \\
\hline $\mathbf{- 1 0}^{\mathbf{0}}$ & $1.07 \mathrm{~m} / \mathrm{s}^{2}$ \\
\hline $\mathbf{- 2 0}^{\mathbf{0}}$ & $2.03 \mathrm{~m} / \mathrm{s}^{2}$ \\
\hline $\mathbf{- 3 0}^{\mathbf{0}}$ & $3.06 \mathrm{~m} / \mathrm{s}^{2}$ \\
\hline $\mathbf{- 4 0}^{\mathbf{0}}$ & $4.06 \mathrm{~m} / \mathrm{s}^{2}$ \\
\hline $\mathbf{- 5 0}^{\mathbf{0}}$ & $5.05 \mathrm{~m} / \mathrm{s}^{2}$ \\
\hline $\mathbf{- 6 0}^{\mathbf{0}}$ & $6.05 \mathrm{~m} / \mathrm{s}^{2}$ \\
\hline $\mathbf{- 7 0}^{\mathbf{0}}$ & $7.09 \mathrm{~m} / \mathrm{s}^{2}$ \\
\hline $\mathbf{- 8 0}^{\mathbf{0}}$ & $8.02 \mathrm{~m} / \mathrm{s}^{2}$ \\
\hline $\mathbf{- 9 0}^{\mathbf{0}}$ & 9.09 \\
\hline
\end{tabular}

\section{Jangkauan Bluetooth}

Diantara spesifikasi bleutooth, ada 2 kelas yang paling popular yaitu, kelas 1 mempunyai jarak jangkauan berkisar \pm 100 meter ( dalam banyak kasus hanya 20-30 meter) dan kelas 2 mempunyai jarak jangkauan berkisar \pm 30 meter ( dalam banyak kasus hanya 5-10 meter). Jangkauan tersebut bisa diakibatkan karena pengaruh atmosfer, geografis, dan perkotaan. Jangkauan yang lebih besar biasanya koneksi pengiriman datanya lebih lambat.

\section{Paramater ukur}

1. Area terbuka

2. Karakter yang dikirim 'a'

3. Jarak pengujian

\section{Pengukuran dan Analisa}

Tabel Hasil Pengujian Jarak Jangkauan Bluetooth

\begin{tabular}{|c|c|c|c|}
\hline Jarak & Data Dikirim & Data Diterima & Keterangan \\
\hline 10 meter & 'a' & 'a' & Berhasil \\
\hline 20 meter & 'a' & 'a' & Berhasil \\
\hline 30 meter & 'a' & 'a' & Berhasil \\
\hline 40 meter & 'a' & 'a' & Berhasil \\
\hline 50 meter & 'a' & 'a' & Berhasil \\
\hline 60 meter & 'a' & - & Gagal \\
\hline
\end{tabular}


Dari table diatas bisa disimpulkan bahwa koneksi antara bluetooth handphone dengan bluetooth modul pada rangkaian digital hanya bisa bekerja maksimal pada jarak \pm 60 meter pada area terbuka tanpa halangan. Hal itu bisa dibuktikan dengan cara setiap jarak 10 meter kita mengirim data dari handphone menuju Bluetooth module. Misalnya kita mengirim data 'a' ( perintah untuk motor 1 pada arm robot bergerak kekiri ) maka data yang diterima oleh Bluetooth modul adalah 'a' ( bisa dilihat pada LCD rangkaian digital ). Dan jika pada saat kirim data 'a' dari handphone ( jarak 60 meter ) maka data yang diterima oleh Bluetooth modul berbeda dengan data yang dikirimkan oleh handphone ( mengirim ' $a$ ' diterima ' $b$ ' / atau mengirim perintah untuk arm robot bergerak kekiri tetapi arm robot bergerak kekanan ). Terkadang bisa juga tidak terkirim perintah data apapun pada jarak tersebut, hal itu menandakan jarak jangkauan Bluetooth tersebut.

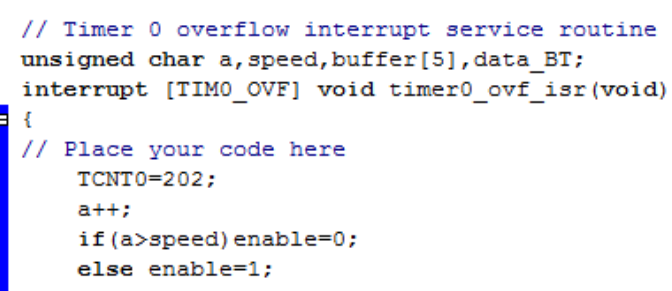

Gambar Tampilan Program

\section{KESIMPULAN}

1. Rancangan control gerak robotic ini menampilkan 2 gerakan dari setiap motor DC yg terdapat pada lengan robot tersebut serta perintah atau inputan diberikan oleh android mobile. Dalam sistem pengendalian robot lengan yang telah dibuat, terdapat 3 modus operasi, yaitu: modus manual, modus otomatis, dan modus computer-based semuanya dapat beroperasi dengan baik sesuai dengan keinginan

2. Rangkaian kendali robot menggunakan koneksi dari android mobile ke rangkaian Bluetooth handphone telah berhasil di lakukan sehingga Salah satu motor pada lengan robot dapat digerakan memakai G-Sensor atau Acelerometer dengan gerakan kekanan dan kekiri dari android

\section{DAFTAR PUSTAKA}

Somby, Michael, Software Platforms for Service Robotics

Pudin, Saripudin, Kendali Motor Servo dengan Pulse Width Modulation (PWM) pada Mikrokontroler AVR

MacKenzie, I Scott; The 8051 Microcontroller New Jersey: Prentice-Hall,Inc.. 1995.

Mair. Gordon M.; Industrial Robotics, Great Britain: Prentice Hall, Inc.. 1988.

Millman \& Halkias; Elektronika Terpadu (Integrated Electronics):Rangkaian dan Sistem Analog dan Digital, Terjemahan: M Barmawi danM O. Tjia. Jakarta: Erlangga, 1993.

Groover, Mikell P.; Nagel, Mitchell Weiss Roger N.; Odrey, Nicholas G.;Industrial Robotics Technology, Programming, and Applications,Singapore: McGraw-Hill, Inc., 1986.

Natawijaya, Finella; Rancang Bangun Ulang Kontroler Robot LenganEDARM ED-7100, Tugas Akhir Jurusan Teknik Komputer - Fakultas limitKomputerUPH, 2006.

Niku. Saeed B; Introduction to Robotics: Analysis, Systems,Applications, New Jersey: Prentice Hall, Inc., 2001.

Stadler Wolfram: Analytical Robotics and Mechatronics SingaporeMcGraw-Hill Inc., 1995 